\title{
$p$-GaN field plate for low leakage current in lateral GaN Schottky Barrier Diodes
}

\author{
Luca Nela $^{1, \mathrm{a}}$, Catherine Erine ${ }^{1}$, and Elison Matioli ${ }^{1, \mathrm{a}}$
}

\begin{abstract}
AFFILIATIONS
${ }^{1}$ Institute of Electrical Engineering, École Polytechnique Fédérale de Lausanne, Lausanne, 1015, Switzerland

a Authors to whom correspondence should be addressed: luca.nela@epfl.ch and elison.matioli@epfl.ch
\end{abstract}

\begin{abstract}
High-voltage Gallium Nitride Schottky Barrier Diodes (SBDs) suffer from large off-state leakage current, which further degrades during operation at high temperatures and limits the device blocking capabilities. The key to achieving low off-state leakage is to protect the Schottky barrier from the high electric field, which is challenging by employing conventional field plate structures due to their large pinch-off voltage. In this work, we propose a simple AlGaN/GaN SBD architecture based on a $p$-GaN cap layer to achieve excellent off-state performance with a very low leakage current. By properly designing the AlGaN barrier and $p$ GaN cap, the pinch off-voltage of the $p$-GaN field plate is carefully controlled and the voltage drop over the Schottky junction is effectively reduced. In addition, a large carrier concentration in the access region is achieved, leading to a reduced sheet resistance. This results in good on-state performance along with a very low leakage current of $\sim 1 \mathrm{nA} / \mathrm{mm}$ at $400 \mathrm{~V}$, which is maintained well below $100 \mathrm{nA} / \mathrm{mm}$ up to elevated temperatures of $150^{\circ} \mathrm{C}$. Besides, the proposed architecture shares the wellestablished fabrication process of commercial $p$-GaN HEMTs and thus represents a promising and viable solution for future GaN diodes.
\end{abstract}

GaN-on-Si power devices have demonstrated great potential for power conversion applications ${ }^{1-3}$. GaN High-Electron-Mobility Transistors (HEMTs) have been commercially available for several years and are gaining a considerable market share. Yet, GaN SBDs have encountered a more difficult development and, at the moment, $\mathrm{SiC}$ diodes represent the main commercial solution. Achieving high-performance GaN SBDs is, however, of great importance for GaN power technology. Indeed, lateral GaN SBDs would provide a competitive alternative to SiC diodes in terms of performance and cost, and would allow the integration of multiple $\mathrm{GaN}$ devices on the same chip to realize power $\mathrm{ICs}^{4-8}$.

The main challenge for GaN SBDs is the difficult management of the off-state electric field at the fragile Schottky barrier, which, if not properly managed, results in a large leakage current that severely limits the device's breakdown voltage. Besides, the blocking performance of GaN SBDs further degrades at elevated temperatures, which is, however, the typical operation condition of wide band-gap power devices. The key to decreasing the high off-state leakage is to reduce the maximum voltage drop on the Schottky barrier by engineering field plate (FP) structures with a pinch-off voltage $\left(V_{\mathrm{P}}\right)$ close to $0 \mathrm{~V}$ aimed at protecting the junction ${ }^{9,10}$. This approach enables depleting the channel region below the FP when a reverse voltage larger than $V_{\mathrm{P}}$ is applied to the device terminals, thus limiting the voltage drop on the Schottky barrier. This is, however, challenging as conventional field plate structures with no oxide already present a rather large negative $V_{\mathrm{P}} \sim$ - (4-5) $\mathrm{V}$, which results in high off-state leakage for the SBD. Alternative strategies proposed in the literature include the use of a Tri-anode architecture ${ }^{5,11-13}$ or the partial recess of the AlGaN barrier ${ }^{10,14}$ to achieve FPs with $V_{\mathrm{P}} \sim-1 \mathrm{~V}$.
Nevertheless, while these approaches have been demonstrated to be effective in reducing the off-state leakage, they require complex processing that is not widely available, and increases the cost and complexity of the device fabrication. In particular, Tri-anode devices need lithographic resolutions of about 100 $\mathrm{nm}^{5,11-13}$ and SBDs with a partially recessed barrier require extremely precise control of the etching depth, which can be reproducibly achieved only by complex methods such as atomic layer etching ${ }^{10,14}$.

Here, we propose a simple AlGaN/GaN SBD architecture based on a $p$-GaN cap layer to achieve excellent off-state performance with a very low off-state leakage current. While approaches based on a $p-\mathrm{GaN}$ edge termination have been investigated, previous works were aimed at very different architectures, such as SBDs with multiple channels ${ }^{15,16}$ or with a Reduced Surface Field ${ }^{17}$ (RESURF) layer ${ }^{18}$. The role of the $p$ $\mathrm{GaN}$ field plate in these structures was not to reduce the offstate leakage but rather to improve the electric field distribution in the drift region, similarly to conventional field plates. For these reasons, the design and physical mechanisms behind the operation of the $p$-GaN field plate differed significantly from the one here presented, which is instead specifically aimed at reducing the off-state leakage. In addition, the design and operation of the proposed $p-\mathrm{GaN}$ field plate are different also compared to conventional enhancement-mode (e-mode) $p$-GaN HEMTs for which the pinch-off voltage should be as positive as possible. In particular, to achieve a low leakage current, the $p$-GaN field plate should be designed to present a slightly negative $V_{\mathrm{P}}$. Indeed, a too negative $V_{\mathrm{P}}$ would result in similar behavior as for conventional FPs ${ }^{15}$, which are not effective in properly protecting the Schottky junction and result in a large off-state leakage. On the contrary, a positive pinch-off voltage 


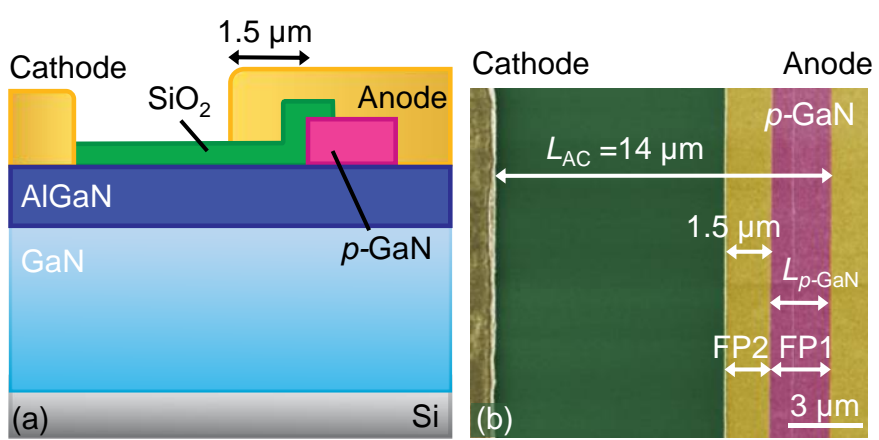

FIG. 1. (a) Schematics and (b) top SEM view of the proposed AlGaN/GaN SBD with $p$-GaN cap field plate in the anode region.

in the $p$-GaN region, as in $p$-GaN e-mode HEMTs would lead to a degradation of the SBD turn-on voltage.

In this work, we show that by properly tuning the AlGaN barrier and $p-\mathrm{GaN}$ cap, a $p-\mathrm{GaN}$ field plate with $V_{\mathrm{P}}$ close to 0 $\mathrm{V}$ is achieved, which effectively limits the voltage drop over the Schottky junction. Besides, tuning the AlGaN barrier also enables to increase the carrier density in the access region compared to usual $p$-GaN based devices, thus leading to a low sheet resistance. This results in good on-state performance combined with a very low leakage current $\sim 1 \mathrm{nA} / \mathrm{mm}$ at $400 \mathrm{~V}$, which is maintained well below $100 \mathrm{nA} / \mathrm{mm}$ up to elevated temperatures of $150^{\circ} \mathrm{C}$. In addition, this architecture shares the well-established fabrication process of commercial $p$-GaN HEMTs and can benefit from the extensive research on these devices, which could significantly accelerate its development.

The devices were fabricated on a GaN-on-Si heterostructure comprising a $5.2 \mu \mathrm{m}$ of buffer, $420 \mathrm{~nm}$ of unintentionally doped $\mathrm{GaN}$ (u-GaN) channel, $0.7 \mathrm{~nm}$ of AlN spacer, $20 \mathrm{~nm}$ of $\mathrm{Al}_{0.25} \mathrm{Ga}_{0.75} \mathrm{~N}$ barrier, and $75 \mathrm{~nm}$ of $p$-GaN cap-layer with a $\mathrm{Mg}$ concentration of $3 \times 10^{19} \mathrm{~cm}^{-3}$. The device fabrication started with the removal of the $p$-GaN cap layer from the access and contact region by a low-damage, slow-etch-rate $\mathrm{Cl}_{2} / \mathrm{Ar}$-based inductively coupled plasma (ICP) etching. The device mesa was defined by ICP etching to a depth of $250 \mathrm{~nm}$. The cathode was formed by a stack of $\mathrm{Ti}(20 \mathrm{~nm}) / \mathrm{Al}(120 \mathrm{~nm}) / \mathrm{Ti}(40 \mathrm{~nm}) / \mathrm{Ni}(60$ $\mathrm{nm}) / \mathrm{Au}(50 \mathrm{~nm})$ and annealed at $780{ }^{\circ} \mathrm{C}$ for $30 \mathrm{~s}$, followed by the deposition of a $25 \mathrm{~nm}$-thick $\mathrm{SiO}_{2}$ layer by atomic layer deposition (ALD). The oxide was patterned by wet etching and a Ni/Au (50 nm / $120 \mathrm{~nm})$ metal stack was evaporated to serve as anode contact.

Figure 1 shows the cross-sectional schematic and the scanning electron microscope (SEM) top-view of the proposed device. The device anode-to-cathode distance $\left(L_{\mathrm{AC}}\right)$ is $14 \mu \mathrm{m}$, measured from the cathode edge to the end of the $p$-GaN FP (Fig. 1(b)), while the device width is $60 \mu \mathrm{m}$. All quantities reported in the manuscript have been normalized by the total device width $(60 \mu \mathrm{m})$. No significant variation of the device performance is expected for scaled-up devices, as verified in Refs. ${ }^{4,5,19}$. Reference devices with fully removed $p$-GaN cap layer and Tri-anode structures were co-fabricated on the same chip.

To reduce the voltage drop on the Schottky barrier during the off-state, the heterostructure should be properly designed. To this end, the $V_{\mathrm{P}}$ of the $p$-GaN field plate (FP1) that protects the Schottky junction (Fig. 1 (a)) should be adjusted to be just slightly negative. Indeed, the value of $V_{\mathrm{P}, \mathrm{FP} 1}$ represents the diode

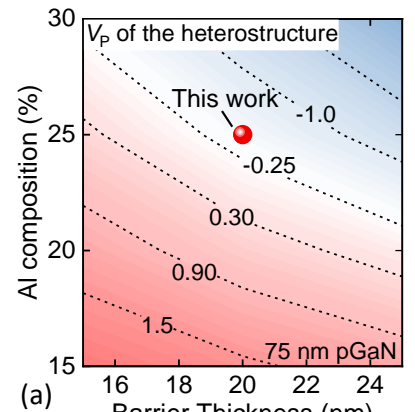

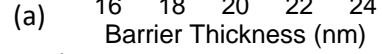
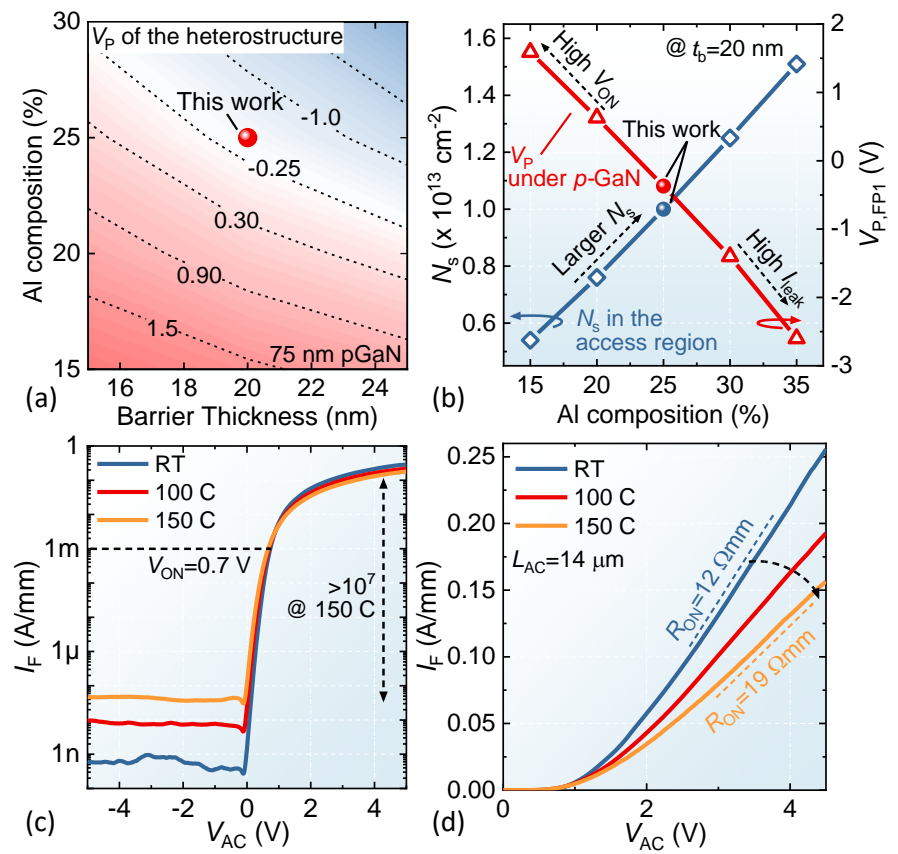

FIG. 2. (a) Simulated $V_{\mathrm{P}}$ of a heterostructure with a $75 \mathrm{~nm}$-thick $p$-GaN layer as a function of the $\mathrm{AlGaN}$ barrier thickness and $\mathrm{Al}$ composition. (b) Simulated $N_{\mathrm{s}}$ in the access region (with no $p$-GaN) and $V_{\mathrm{P}}$ under the $p$-GaN cap for a 20 $\mathrm{nm}$-thick $\mathrm{AlGaN}$ barrier as a function of its $\mathrm{Al}$ composition. (c) I-V curves for the proposed $p$-GaN SBD in logarithmic (c) and linear (d) scale at different temperatures. $V_{\mathrm{AC}}$ represents the anode-to-cathode voltage.

anode-to-cathode voltage $\left(V_{\mathrm{AC}}\right)$ for which the region under the field plate 1 is depleted, limiting the voltage drop over the Schottky barrier. Too positive $V_{\mathrm{P}, \mathrm{FP} 1}$ would result in a degraded diode turn-on voltage while too negative values would lead to a large leakage current, as shown in the following sections. While varying the thickness and doping of the $p$-GaN layer does not impact significantly the $V_{\mathrm{P}}$ of the $p$-GaN field plate, tuning the AlGaN barrier is an effective approach to set the $V_{\mathrm{P}, \mathrm{FP} 1}$. Figure 2 (a) illustrates the simulated $V_{\mathrm{P}}$ of a heterostructure with a 75 nm-thick $p$-GaN cap layer as a function of the AlGaN barrier thickness and composition. The simulation was performed by Atlas Silvaco software. The $20 \mathrm{~nm}$-thick $\mathrm{Al}_{0.25} \mathrm{Ga}_{0.75} \mathrm{~N}$ barrier employed in this work results in a $V_{\mathrm{P}, \mathrm{PP} 1} \sim-0.4 \mathrm{~V}$, which satisfies the requirements aforementioned. Besides, the use of a $20 \mathrm{~nm} \mathrm{Al}_{0.25} \mathrm{Ga}_{0.75} \mathrm{~N}$ barrier, which is thicker and with higher $\mathrm{Al}$ composition than for usual $p$-GaN based devices, leads to a large two-dimensional electron gas (2DEG) concentration $\left(N_{\mathrm{s}}\right)$ in the access region (where the $p-\mathrm{GaN}$ cap is removed) (Fig. 2 (b)). This results in a low sheet resistance $\left(R_{\mathrm{sh}}\right)$ in the drift region, which reduces the device on-resistance. Finally, while the proposed structure differs from the typical $p$-GaN heterostructures used for e-mode transistors, it was shown that e-mode devices can be realized on this platform by employing a Tri-gate architecture ${ }^{20}$, hence enabling the integration of emode HEMTs and SBDs on the same chip.

Figure 2 (c-d) presents the I-V curve for the proposed devices. The SBD shows a turn-on voltage $\left(V_{\mathrm{ON}}\right)$ of $0.7 \mathrm{~V}$ at $1 \mathrm{~mA} / \mathrm{mm}$ (Fig. 2 (c)), which is a typical value for $\mathrm{Ni} / \mathrm{Au}$ anode contact ${ }^{12,21}$ and confirms no degradation in the diode turn-on due to the $p$ $\mathrm{GaN}$ layer. Besides, thanks to the effective $p$-GaN field plate, an excellent $I_{\mathrm{ON}} / I_{\mathrm{OFF}}$ above $10^{9}$ at room temperature (RT) is obtained, whose value is maintained above $10^{7}$ even at $150{ }^{\circ} \mathrm{C}$. The large $N_{\mathrm{s}}$ in the access region also results in a low $R_{\mathrm{ON}}$ of 12 

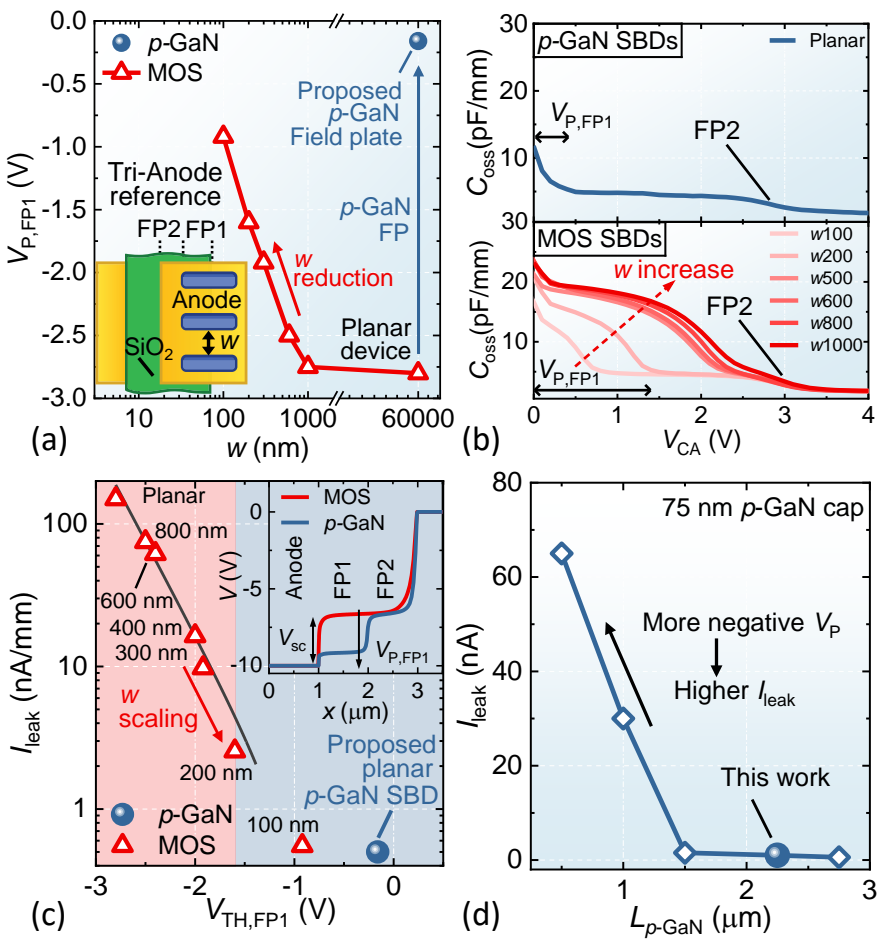

FIG. 3. (a) $V_{\mathrm{P}, \mathrm{PP} 1}$ as a function of the nanowire width for $p-\mathrm{GaN}$ and MOS devices. The bottom-left inset shows the schematics of the reference Tri-Anode devices. (b) Output capacitance for $p$-GaN and MOS SBDs Tri-anode devices having different nanowire width (c) SBD leakage current (extracted at $20 \mathrm{~V}$ ) as a function of the $V_{P, F P 1}$. The inset shows the potential distribution close to the anode electrode for $p-\mathrm{GaN}$ and reference MOS SBDs for $V_{\mathrm{AC}}$ of $-10 \mathrm{~V}$. $V_{\mathrm{sc}}$ is the voltage drop on the Schottky barrier (d) Off-state current as a function of the $p$-GaN FP lengths $\left(L_{p-\mathrm{GaN}}\right)$.

$\Omega \cdot \mathrm{mm}$ for a $L_{\mathrm{AC}}$ of $14 \mu \mathrm{m}$ (Fig. 2 (d)), which increases to 19 $\Omega \cdot \mathrm{mm}$ at $150{ }^{\circ} \mathrm{C}$, showing the device's potential to operate at high temperatures. It should be noted that the majority of the on-state current goes through the AlGaN/anode metal interface (Fig. 1 (a)) rather than through the $p$-GaN layer, which was verified both by TCAD simulations and experimentally. Indeed, the presence of an anode region in direct contact with the $\mathrm{AlGaN}$ barrier is fundamental to ensure low $V_{\mathrm{ON}}$ and $R_{\mathrm{ON}}$, which would otherwise be degraded by the conduction through the $p$-GaN layer.

To investigate the role of the $p$-GaN field plate in reducing the SBD off-state leakage, reference MOS Tri-anode devices (inset in Fig. 3 (a)), like the ones presented in Ref. ${ }^{5,11-13}$, were considered. While the proposed $p$-GaN SBDs are based on a conventional planar architecture (see Fig. 1), the use of a Trianode enables a gradual tuning of the field plate 1 pinch-off voltage $\left(V_{\mathrm{P}, \mathrm{FP} 1}\right.$, Fig. 1 (b)). This provides a more complete understanding of the physical mechanisms involved and enables deriving a relation between $V_{\mathrm{P}, \mathrm{FP} 1}$ and the leakage current. However, while employing a Tri-anode architecture is a convenient method to gradually shift $V_{\mathrm{P}, \mathrm{PP} 1}$, the conclusions of the proposed analysis are general. Indeed, they also apply to other techniques such as the use of a $p$-GaN cap layer (as here presented) or the partial recess of the barrier ${ }^{10,14}$. In addition, while the device $L_{\mathrm{AC}}$ influences the breakdown voltage, the value of the off-state current up to a few hundred Volts is mainly determined by the leakage through the Schottky barrier. Thus the presented analysis is general and can be applied to SBDs with different lengths. Figure 3 (a) shows that a planar
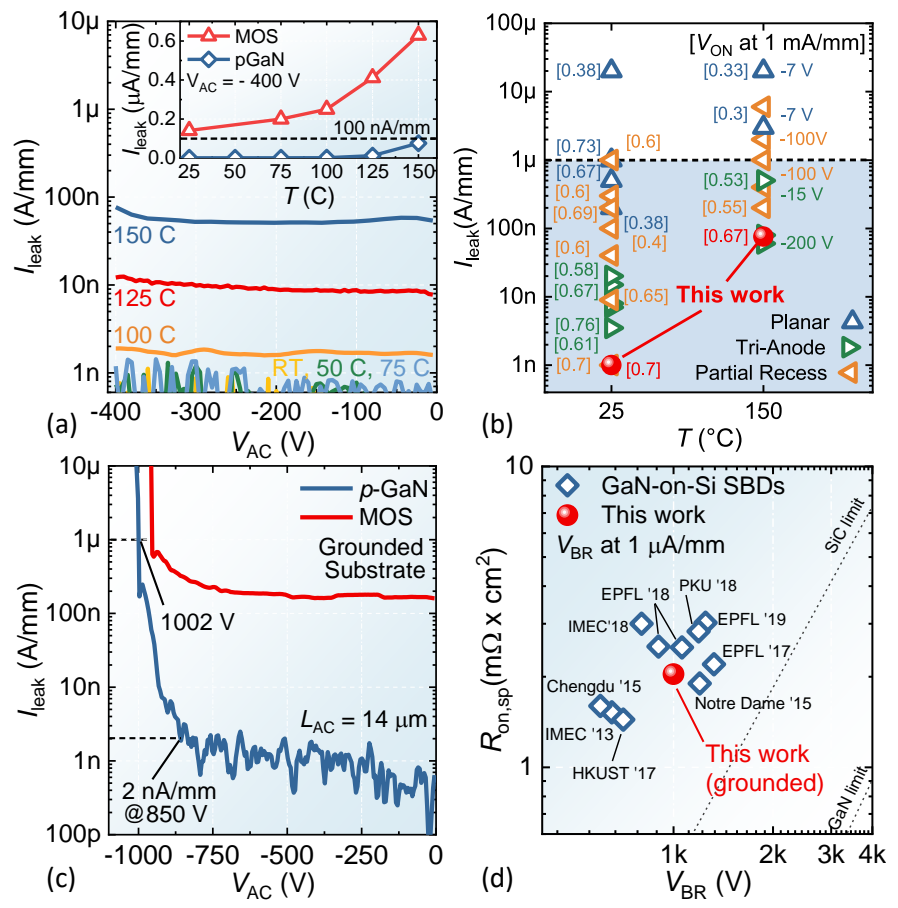

FIG. 4. (a) Off-state leakage current for a $p$-GaN SBD at different temperatures. Inset: $I_{\text {leak }}$ as a function of temperature at a reverse voltage of $400 \mathrm{~V}$ for a planar $p$-GaN and MOS SBD (b) $I_{\text {leak }}$ at RT and $150{ }^{\circ} \mathrm{C}$ for state-of-the-art SBDs present in the literature $5,10,28-32,12-14,21,24-27$. The corresponding diode $V_{\mathrm{ON}}$ is shown in brackets. The off-state voltage is $400 \mathrm{~V}$ unless differently specified (c) Breakdown curve for a planar $p$-GaN and MOS SBD with $L_{\mathrm{AC}}$ of $14 \mu \mathrm{m}$ and grounded substrate. (d) $R_{\mathrm{ON}, \mathrm{sp}}$ vs $V_{\mathrm{BR}}$ benchmark for the proposed $p$-GaN SBD compared to state-of-the-art GaN-on-Si lateral SBDs present in the literature $5,12,13,21,24,26,29-32$. The breakdown has been defined at an off-state current of 1 $\mu \mathrm{A} / \mathrm{mm}$ and a $3 \mu \mathrm{m}$ transfer length, adding up to $L_{\mathrm{AC}}$, has been considered to evaluate $R_{\mathrm{ON}, \mathrm{sp}}$.

MOS field-plate presents a rather negative $V_{\mathrm{P}, \mathrm{FP} 1}$ of $-2.8 \mathrm{~V}$, which reduces as the Tri-anode widths (w) decreases (Fig. 3 (a), red arrow). On the contrary, the proposed $p$-GaN field plate enables achieving slightly negative $(-0.25 \mathrm{~V}) V_{\mathrm{P}, \mathrm{PP} 1}$ even for a planar device (Fig. 3 (a), blue arrow), in agreement with the simulation in Fig. 2 (a-b). This behavior is confirmed by the SBD output capacitance $\left(C_{\text {oss }}\right)$ (Fig. 3 (b)), which shows a very small $V_{\mathrm{P}, \mathrm{FP} 1}$ for $p$-GaN devices, and an instead rather large $V_{\mathrm{P}, \mathrm{FP} 1}$ for MOS devices, with a strong dependence on $w$. The role of $V_{\mathrm{P}, \mathrm{FP} 1}$ is fundamental as it represents the voltage drop over the Schottky barrier $\left(V_{\mathrm{sc}}\right)$ (inset of Fig. 3 (c)) and directly determines the electric field at the barrier and the SBD leakage current $\left(I_{\text {leak }}\right)^{9,13}$, as shown in Fig. 3 (c). Indeed, negative values below $\sim-2 \mathrm{~V}$ of $V_{\mathrm{P}, \mathrm{FP} 1}$ result in an exponential increase of the SBD leakage current due to the enhanced conduction through the Schottky barrier. On the contrary, the small $V_{\mathrm{P}, \mathrm{FP} 1}$ of $p$-GaN SBDs results in a very low leakage $<1 \mathrm{nA} / \mathrm{mm}$ even for planar devices, proving the effectiveness of the proposed approach. It should be noted that while a similar approach based on a $p$-GaN layer was proposed for field-effect rectifier ${ }^{22,23}$, this typically results in a large off-state current due to the very strong dependence of $I_{\text {leak }}$ on the exact $V_{\mathrm{P}, \mathrm{FP} 1}$ value. In the proposed $p$ GaN SBDs, the presence of a Schottky barrier allows more tolerance on $V_{\mathrm{P}, \mathrm{FP} 1}(\mathrm{Fig} .3$ (c)), enabling to achieve extremely low off-state leakage. Another important aspect to consider when designing the $p$-GaN FP is the $V_{\mathrm{P}, \mathrm{FP} 1}$ dependence on its length. Indeed, for too short FP lengths $\left(L_{p-\mathrm{GaN}}\right)$, the field plate pinch-off voltage reduces, as shown in Ref. ${ }^{20}$, which results in 
an increase of the leakage current (Fig. 3 (d)). On the contrary, $L_{p \text {-GaN }}$ values above $1.5 \mu \mathrm{m}$ ensure $V_{\mathrm{P}, \mathrm{FP} 1}$ close to $0 \mathrm{~V}$ and a considerable reduction of the off-state leakage.

Thanks to the small voltage drop on the Schottky barrier, the proposed $p$-GaN SBDs results in very low leakage current even during high-temperature operation with $I_{\text {leak }} \sim 2 \mathrm{nA} / \mathrm{mm}$ at 400 $\mathrm{V}$ and $100{ }^{\circ} \mathrm{C}$, and well below $100 \mathrm{nA} / \mathrm{mm}$ at $150{ }^{\circ} \mathrm{C}$ (Fig. 4 (a)). This offers an important advantage over devices with no $p$ GaN FP that instead show a large leakage increase at high temperatures (inset in Fig. 4 (a)). In particular, the presented $p$ GaN SBDs show a largely reduced leakage current both at RT and $150{ }^{\circ} \mathrm{C}$ compared to state-of-the-art devices based on a planar field plate strategy (Fig. 4 (b)). They also show very competitive performance compared to Tri-anode and partially recessed devices, which however require a much more complex fabrication process. Finally, the $p$-GaN SBDs present a breakdown voltage of $1 \mathrm{kV}$ at $1 \mu \mathrm{A} / \mathrm{mm}$ for a $L_{\mathrm{AC}}$ of $14 \mu \mathrm{m}$, showing a significant leakage current reduction compared to reference MOS devices with $I_{\text {leak }}$ below $2 \mathrm{nA} / \mathrm{mm}$ up to $V_{\mathrm{AC}}$ of $-850 \mathrm{~V}$ (Fig. 4 (c)). This results in an excellent $R_{\mathrm{ON}, \mathrm{sp}}$ vs $V_{\mathrm{BR}}$ benchmark for the proposed $p$-GaN SBDs compared with stateof-the-art GaN-on-Si lateral SBDs in the literature (Fig. 4 (d)), which proves the great potential of the proposed devices for power conversion applications.

In conclusion, in this work, we proposed an $\mathrm{AlGaN} / \mathrm{GaN}$ SBD architecture based on a $p$-GaN cap layer to achieve excellent off-state performance with a very low off-state leakage current. By a proper design of the heterostructure, the voltage drop over the Schottky junction was effectively reduced while a large carrier density in the access region was achieved. This led to good on-state performance combined with a very low leakage current both at RT and up to $150{ }^{\circ} \mathrm{C}$. Finally, the proposed device is particularly appealing as it shares the well-established fabrication process of commercial $p$-GaN HEMTs and thus represents a promising and viable solution for future $\mathrm{GaN}$ SBDs.

This work was supported in part by Swiss National Science Foundation through the Assistant Professor (AP) Energy under Grant PYAPP2 166901 and in part by Swiss and in part by the ECSEL Joint Undertaking (JU) under Grant 826392. The JU receives support from the European Union's Horizon 2020 Research and Innovation Program and Austria, Belgium, Germany, Italy, Norway, Slovakia, Spain, Sweden, and Switzerland.

\section{Data Availability}

The data that support the findings of this study are available from the corresponding author upon reasonable request.

\section{REFERENCES}

${ }^{1}$ K.J. Chen, O. Haberlen, A. Lidow, C.L. Tsai, T. Ueda, Y. Uemoto, and Y. Wu, IEEE Trans. Electron Devices 64, 779 (2017).

${ }^{2}$ H. Amano, Y. Baines, E. Beam, M. Borga, T. Bouchet, P.R. Chalker, M. Charles, K.J. Chen, N. Chowdhury, R. Chu, C. De Santi, M.M. De Souza, S. Decoutere, L. Di Cioccio, B. Eckardt, T. Egawa, P. Fay14, J.J. Freedsman, L. Guido, O. Häberlen, G. Haynes, T. Heckel, D. Hemakumara, P. Houston, J. Hu, M. Hua, Q. Huang, A. Huang, S. Jiang, H. Kawai, D. Kinzer, M. Kuball, A. Kumar, K.B. Lee, X. Li, D. Marcon, M. März, R. McCarthy, G. Meneghesso,
M. Meneghini, E. Morvan, A. Nakajima, E.M.S. Narayanan, S. Oliver, T. Palacios, D. Piedra, M. Plissonnier, R. Reddy, M. Sun, I. Thayne, A. Torres, N. Trivellin, V. Unni, M.J. Uren, M. Van Hove, D.J. Wallis, J. Wang, J. Xie, S. Yagi, S. Yang, C. Youtsey, R. Yu, E. Zanoni, S. Zeltner, and Y. Zhang, J. Phys. D. Appl. Phys. 51, 163001 (2018).

${ }^{3}$ M. Meneghini, C. De Santi, I. Abid, M. Buffolo, M. Cioni, R.A. Khadar, L. Nela, N. Zagni, A. Chini, F. Medjdoub, G. Meneghesso, G. Verzellesi, E. Zanoni, and E. Matioli, J. Appl. Phys. 130, 227 (2021).

${ }^{4}$ L. Nela, R. Van Erp, G. Kampitsis, H.K. Yildirim, J. Ma, and E. Matioli, IEEE Trans. Power Electron. 36, 1269 (2020).

${ }^{5}$ L. Nela, G. Kampitsis, J. Ma, and E. Matioli, IEEE Electron Device Lett. 41, 99 (2020).

${ }^{6}$ X. Li, K. Geens, W. Guo, S. You, M. Zhao, D. Fahle, V. Odnoblyudov, G. Groeseneken, and S. Decoutere, IEEE Electron Device Lett. PP, 1 (2019).

${ }^{7}$ R. Reiner, P. Waltereit, B. Weiss, S. Moench, M. Wespel, S. Müller, R. Quay, and O. Ambacher, IET Power Electron. 11, 681 (2017).

${ }^{8}$ R. Reiner, P. Waltereit, B. Weiss, M. Wespel, M. Mikulla, R. Quay, and O. Ambacher, PCIM Eur. 10 (2016).

9 J. Ma, D.C. Zanuz, and E. Matioli, IEEE Electron Device Lett. 38, 1298 (2017).

${ }^{10}$ J. Hu, S. Stoffels, S. Lenci, B. De Jaeger, N. Ronchi, A.N. Tallarico, D. Wellekens, S. You, B. Bakeroot, G. Groeseneken, and S. Decoutere, IEEE Trans. Electron Devices 63, 3451 (2016).

${ }^{11}$ E. Matioli, B. Lu, and T. Palacios, IEEE Trans. Electron Devices 60, 3365 (2013).

${ }^{12}$ J. Ma and E. Matioli, IEEE Electron Device Lett. 38, 83 (2017).

${ }^{13}$ J. Ma and E. Matioli, Appl. Phys. Lett. 112, (2018).

${ }^{14}$ S. Lenci, J. Hu, N. Ronchi, and S. Decoutere, Proc. Int. Symp. Power Semicond. Devices ICs 91 (2016).

${ }^{15}$ M. Xiao, Y. Ma, K. Cheng, K. Liu, A. Xie, E. Beam, Y. Cao, and Y. Zhang, IEEE Electron Device Lett. 41, 1177 (2020).

${ }^{16}$ M. Xiao, Y. Ma, K. Liu, K. Cheng, and Y. Zhang, IEEE Electron Device Lett. 42, 808 (2021).

${ }^{17}$ A.W. Ludikhuize, Int. Symp. Power Semicond. Devices ICs 11 (2000).

${ }^{18}$ S.W. Han, J. Song, S.H. Yoo, Z. Ma, R.M. Lavelle, D.W. Snyder, J.M. Redwing, T.N. Jackson, and R. Chu, IEEE Electron Device Lett. 41, 1758 (2020).

${ }^{19}$ L. Nela, G. Kampitsis, H.K. Yildirim, R. Van Erp, J. Ma, and E. Matioli, Proc. Int. Symp. Power Semicond. Devices ICs 517 (2020).

${ }^{20}$ M. Zhu, C. Erine, J. Ma, M.S. Nikoo, L. Nela, P. Sohi, and E. Matioli, IEEE Electron Device Lett. 42, 82 (2021).

${ }^{21}$ M. Zhu, B. Song, M. Qi, Z. Hu, K. Nomoto, X. Yan, Y. Cao, W. Johnson, E. Kohn, D. Jena, and H.G. Xing, IEEE Electron Device Lett. 36, 375 (2015).

${ }^{22}$ M. Basler, R. Reiner, S. Moench, P. Waltereit, R. Quay, I. Kallfass, and O. Ambacher, IEEE Electron Device Lett. 41, 993 (2020).

${ }^{23}$ K.P. Hsueh, Y.S. Chang, B.H. Li, H.C. Wang, H.C. Chiu, C.W. Hu, and R. Xuan, Mater. Sci. Semicond. Process. 90, 107 (2019).

${ }^{24}$ S. Lenci, B. De Jaeger, L. Carbonell, J. Hu, G. Mannaert, D. Wellekens, S. You, B. Bakeroot, and S. Decoutere, IEEE Electron Device Lett. 34, 1035 (2013).

${ }^{25}$ T. Zhang, Y. Lv, R. Li, Y. Zhang, Y. Zhang, X. Li, J. Zhang, and Y. Hao, IEEE Electron Device Lett. (2021).

${ }^{26}$ Q. Zhou, Y. Jin, Y. Shi, J. Mou, X. Bao, B. Chen, and B. Zhang, IEEE Electron Device Lett. 36, 660 (2015).

${ }^{27}$ T. Zhang, J. Zhang, H. Zhou, Y. Wang, T. Chen, K. Zhang, Y. Zhang, K. Dang, Z. Bian, J. Zhang, S. Xu, X. Duan, J. Ning, and Y. Hao, IEEE Electron Device Lett. 40, 1583 (2019).

${ }^{28}$ C.W. Tsou, K.P. Wei, Y.W. Lian, and S.S.H. Hsu, IEEE Electron Device Lett. 37, 70 (2016).

${ }^{29}$ J. Lei, J. Wei, G. Tang, Z. Zhang, Q. Qian, Z. Zheng, M. Hua, and K.J. Chen, IEEE Electron Device Lett. 39, 260 (2018).

${ }^{30}$ J. Gao, Y. Jin, B. Xie, C.P. Wen, Y. Hao, B. Shen, and M. Wang, IEEE Electron Device Lett. 39, 859 (2018).

${ }^{31}$ J. Ma, G. Kampitsis, P. Xiang, K. Cheng, and E. Matioli, IEEE Electron Device Lett. 40, 275 (2018).

32 J. Ma, M. Zhu, and E. Matioli, IEEE Electron Device Lett. 38, 1704 (2017). 